\title{
PRINCIPLES AND APPLICATIONS OF CERAMIC HUMIDITY SENSORS
}

\author{
MARIO PELINO AND CARLO CANTALINI \\ Department of Chemistry, Chemical Engineering and Materials, 67040 Monteluco di Roio, \\ L'Aquila, Italy \\ MARCO FACCIO \\ Department of Electrical Engineering, 67040 Monteluco di Roio, L'Aquila, Italy
}

(Received July 10, 1993; in final form August 28, 1993)

This paper presents a brief review of the state of the art in humidity and gas ceramic sensors R\&D; it also describes the principle, fabrication and application of the humidity-sensitive Si-doped $\alpha$-hematite $\left(\alpha-\mathrm{Fe}_{2} \mathrm{O}_{3}\right)$ sintered compacts.

The humidity signal response is characterized by volt-amperometric and impedance spectroscopy techniques in the $0-97 \%$ relative bumidity $(\mathrm{RH})$ range. The response time of the sensor is evaluated by $0-60 \%$ RH variations. Experimental techniques used to measure the hysteresis, drift, and aging of the humidity sensor are presented and the results are discussed. The $\mathrm{CO}$ sensitivity is investigated by activating the sensor in the $350-450{ }^{\circ} \mathrm{C}$ temperature range.

A humidity-meter prototype, based on the $\alpha-\mathrm{Fe}_{2} \mathrm{O}_{3}$ ceramic compact is described, and its electronics and features are presented in this paper.

\section{INTRODUCTION}

Sensors are key elements in the rapidly evolving fields of measurements, instrumentations, and automated systems. The recent progresses made in improving the reliability and lowering the cost of microprocessors and interface circuits has resulted in a higher demand for sensors, which convert physical or chemical quantities in various environments into electrical signal. Different functions and materials have been investigated, and several devices have been put on the market or have become part of sophisticated instrumentations ${ }^{1}$.

Among these materials, functional ceramics have played a major role because of their intrinsic characteristics: they are superior in mechanical strength and chemical resistence in most environments and in the reproducibility of the electrical properties. They have also been widely used to satisfy diverse needs for sensing devices, and consistent results have been obtained in the field of atmospheric sensors, i.e., temperature ${ }^{2}$, humidity ${ }^{3-8}$, and gas sensors ${ }^{9-12}$.

It is well known bulk ceramics are prepared by a relatively simple process consisting of mixing raw materials, forming the part, and sintering. Ceramics are characterized by their unique structure consisting of crystal grains, grain boundaries and, when they are porous, by large surface intra- and inter-granular pores. Both high density and porous ceramics are easily produced by controlling the compact 
forming and sintering conditions. Furthermore, in ceramic materials, solid solution or doping can be easily formed and improved properties are relatively easy to obtain $^{13.14}$.

Sensitive thick ceramic films can be obtained by the screen printing and firing technique ${ }^{15-16}$, while the radio frequency sputtering ${ }^{17}$, chemical vapor deposition ${ }^{18}$ and the sol-gel processes ${ }^{19}$ enable one to deposit thin ceramic films on different substrates.

In Table I, several ceramic materials with their sensor property and function are reported. The humidity sensitivity property is not included in the table because it will be extensively discussed in the next section.

In porous ceramics, the surface and open pores tend to collect water vapor and gases through chemical and physical adsorption and through condensation ${ }^{20-24}$. Especially in semiconductor ceramics, electrical properties are largely related to the grain size and the pore size distribution of the open pores. The pore surface conductivity changes with even small variations in the humidity or with the adsorption of various gases. Porosity-controlled ceramics are suitable for atmospheric sensing such as humidity and gas sensors.

As noted above, humidity or gas sensors are usually exposed to atmospheric conditions containing various other components. They tend to lose their inherent sensitive properties during use because of a number of complicated physical and chemical processes that occur between these components and the material. Major

TABLE I

Ceramic sensors: Properties, Materials and Functions.

\begin{tabular}{|c|c|c|}
\hline Sensor & Sensor Ceramic Material & Sensor Function \\
\hline \multirow[t]{3}{*}{ Temperature } & $\begin{array}{l}(\mathrm{Mn}, \mathrm{Cu})(\mathrm{Mn}, \mathrm{Co}, \mathrm{Ni})_{2} \mathrm{O}_{4} \\
\mathrm{CoAl}_{2} \mathrm{O}_{4} ; \mathrm{NiAl}_{2} \mathrm{O}_{4} ; \mathrm{SiC} \\
\mathrm{Mg}(\mathrm{Al}, \mathrm{Cr}, \mathrm{Fe})_{2} \mathrm{O}_{4}\end{array}$ & NTC thermistor \\
\hline & $\mathrm{BaTiO}_{3}$ & PTC thermistor \\
\hline & $\mathrm{VO}_{2},(\mathrm{Mn}, \mathrm{Zn}) \mathrm{Fe}_{2} \mathrm{O}_{4}$ & Temperature switch \\
\hline \multirow{4}{*}{ Gas } & $\begin{array}{l}\mathrm{SnO}_{2} ; \mathrm{ZnO} ; \gamma-\mathrm{Fe}_{2} \mathrm{O}_{3} \\
\alpha-\mathrm{Fe}_{2} \mathrm{O}_{3} ; \mathrm{WO}_{3}\end{array}$ & $\begin{array}{l}\mathrm{Ch}_{4} ; \mathrm{i}-\mathrm{C}_{4} \mathrm{H}_{10} ; \mathrm{CO} ; \mathrm{SO}_{2} ; \mathrm{NO} ; \mathrm{H}_{2} \mathrm{~S} ; \\
\mathrm{NH}_{3} ;\end{array}$ \\
\hline & $\mathrm{In}_{2} \mathrm{O}_{3}$ & Ozone \\
\hline & $\begin{array}{l}\text { Perovskite type: } \mathrm{XYO}_{3}(\mathrm{X}: \mathrm{Sr} \\
\mathrm{Mg}, \mathrm{Ba}, \mathrm{Ca})(\mathrm{Y}: \mathrm{Zr}, \mathrm{Sn}, \mathrm{Ti} \\
\mathrm{Ce})\end{array}$ & Air/Fuel Ratio \\
\hline & $\mathrm{TiO}_{2} ; \mathrm{CoO}-\mathrm{MgO} ; \mathrm{MgO} ; \mathrm{Y}_{2} \mathrm{O}_{3}$ & $\mathrm{O}_{2}$ \\
\hline Ion & $\begin{array}{l}\mathrm{AgX}(\mathrm{X}: \mathrm{Cl}, \mathrm{Br}, \mathrm{I}, \mathrm{CN}, \mathrm{SCN}) \\
\mathrm{PbS}-\mathrm{Ag}_{2} \mathrm{~S} ; \mathrm{CdS}-\mathrm{Ag}_{2} \mathrm{~S} \\
\mathrm{CuS}-\mathrm{Ag}_{2} \mathrm{~S} ; \mathrm{LaF}_{3}\end{array}$ & Ion selective electrode \\
\hline Position-Velocity & $\mathrm{Pb}(\mathrm{Zr}, \mathrm{Ti}) \mathrm{O}_{3}$ & Piezoelectricity \\
\hline \multirow[t]{2}{*}{ Optics } & $\begin{array}{l}\mathrm{PbTiO}_{3} ; \mathrm{LiTaO}_{3} \\
\mathrm{LiNbO}_{3} ; \mathrm{Pb}(\mathrm{Zr}, \mathrm{Ti}) \mathrm{O}_{3}\end{array}$ & $\begin{array}{l}\text { Pyroelectricity } \\
\text { (Infrared detection) }\end{array}$ \\
\hline & $\mathrm{CaF}_{2} ; \mathrm{Li}_{2} \mathrm{~B}_{4} \mathrm{O}_{7}$ & Thermoluminescence \\
\hline
\end{tabular}


research efforts are directed towards developing highly reliable functional ceramic materials. In addition, most ceramics are not single functional but multifunctional. Therefore, the key to success in developing a single functional material is the technology of masking undesired functions.

The absence of selectivity is considered limiting for the employment of some ceramics as sensors. Today electronic technology is making full use of the intrinsic multiple function of the sensor and multifunctional devices are now being developed. These devices can perform various functions with a single element. As an example, in atmospheric-type sensors, there is an increasing demand for multifunctional sensors that can simultaneously and independently measure both the humidity and another gas, or the humidity and the temperature.

Thus, attempts to make multifunctional devices are directed towards making active use of the intrinsic multiple function of the materials. In developing multifunctional devices, it is important to establish the technology that can discriminate signals without cross-talk, in place of the conventional masking technology. Recently, the technology of sensor arrays through by multicomponent analysis has been developed. This technique makes use of the pattern recognition method in which selectivity can be obtained by comparing the measured signal vector with corresponding vectors of group of sensors, which are obtained by independent calibration ${ }^{25}$.

Pressure, chemical and gas sensors will have the highest ratio of growth (about 2.5 ) by the year 2000. Increasing fields of application of the sensor technology, in Europe, will be the plant construction and process technology, cars and transportation vehicles and the construction and safety technology ${ }^{26}$.

We have developed a humidity sensor based on microporous $\alpha-\mathrm{Fe}_{2} \mathrm{O}_{3}$ and a humidity-meter prototype has been assembled and tested. The multifunctional sensitivity of $\alpha-\mathrm{Fe}_{2} \mathrm{O}_{3}$ to humidity and carbon monoxide is now being used to produce a multifunctional device able to detect these gases in the environmental conditions.

In this report, state-of-the-art ceramic humidity sensors are discussed and experimental results summarizing our efforts on $\alpha-\mathrm{Fe}_{2} \mathrm{O}_{3}$ humidity and $\mathrm{CO}$ sensitivity are presented.

\section{CERAMIC HUMIDITY SENSORS}

As humidity is a permanent environmental factor, its control and measurement are particularly important not only for human comfort but also for many industries and technologies. In recent years, major domestic applications of humidity sensors have been the automatic humidity control in air conditioners and the automatic cooking in microwave ovens. In chemical and alimentary industries and in the production of electronic devices, rapid and accurate humidity control is of critical importance. Citation deserves the wide development of greenhouse agriculture that requires accurate sensors for simultaneous control of temperature and humidity.

Among the possible humidity measurements, Relative Humidity $(\mathrm{RH})$ in percentage, that is the ratio of the actual water pressure to the saturated pressure, is 
the most widely used. As highlighted by several Authors ${ }^{4.7 .8}$, a humidity sensor needs to satisfy several requirements to fulfill a wide range of applications: 1) sensitivity in a wide RH range, 2) rapid response to the variation of RH and good reproducibility of the electrical signal, 3) good mechanical properties and durability, 4) resistence to contaminants, 5) insignificant or predictable dependence on temperature, 6) possibility of masking undesired functions, 7) fitness to circuitry, and 8 ) simple structure and low cost.

To fulfill these characteristics in response to the various demands, several types of humidity sensors have been investigated and developed functioning by means of many physical and chemical phenomena. They are usually clasified into electrolytes, organic polymers and porous ceramics.

Since water evaporates or condenses in an electrolyte depending on the $\mathrm{RH}$ of the environment, the electrolyte-type sensors ${ }^{27}$ utilize the variation of ionic conductivity as a function of RH. The polymeric and ceramic sensors work utilizing the mechanism of the chemical and physical adsorption of water vapor on the surface of the material in a quantity that is proportional to the $\mathrm{RH}$ of the surrounding environment. The adsorption generates a consequent variation of the capacitance or impedance.

The polymeric type hygrometer consists of a capacitor with a hygroscopic polymer dielectric. The difference in relative dielectric constants between the polymer (between 3 to 6$)$ and the water $\left(\epsilon_{\mathrm{r}}=78.54\right.$ at $\left.25^{\circ} \mathrm{C}\right)$ generates a considerable variation in capacitance when water is absorbed ${ }^{28}$.

In ceramic sensors, the type of conduction mechanism can be ionic or electronic: in the ionic mechanism, the impedance of the sensor element decreases with an increase in the RH due to the physisorption and capillary condensation of water molecules on the surface of the material ${ }^{20-24}$. In the electronic type, the logarithm of the conductivity of the element changes linearly with the logarithm of the water vapor concentration. Water molecules act as an electron donating gas and their chemisorption increases or decreases the electronic conductivity depending on whether the material is a $\mathrm{n}$ or $\mathrm{p}$-type semiconductor ${ }^{29}$. In general, it can be asserted that most sensors, in spite of the differences in materials, utilize a common phenomenon that is the chemical and physical adsorption of water molecules on the surface and capillary condensation in the open pores of the microstructure.

In the next section, the mechanism of water interaction with solid surface, metal oxides in particular, is explained through the most significant interaction theories.

In Table II, the materials used to realize the humidity sensors, the principle, the range of application and temperature are summarized.

\section{Mechanism of Water Interaction With Solid Surfaces}

The mechanism of interaction of water vapor molecules with a porous metal oxide is explained by Morimoto ${ }^{20}$ and Zettlemoyer ${ }^{21}$. It is proposed that the water vapor chemisorbs on the surface of a metal-oxide to form hydroxyl groups: the hydroxyl group adsorbed on the surface metal cation and the proton forming a second hydroxyl group with an adjacent surface $\mathrm{O}_{2}$-ion.

As highlighted by IR investigation, the first layer of physisorbed water results in doubly hydrogen bonded to the chemisorbed hydroxyls and is practically im- 


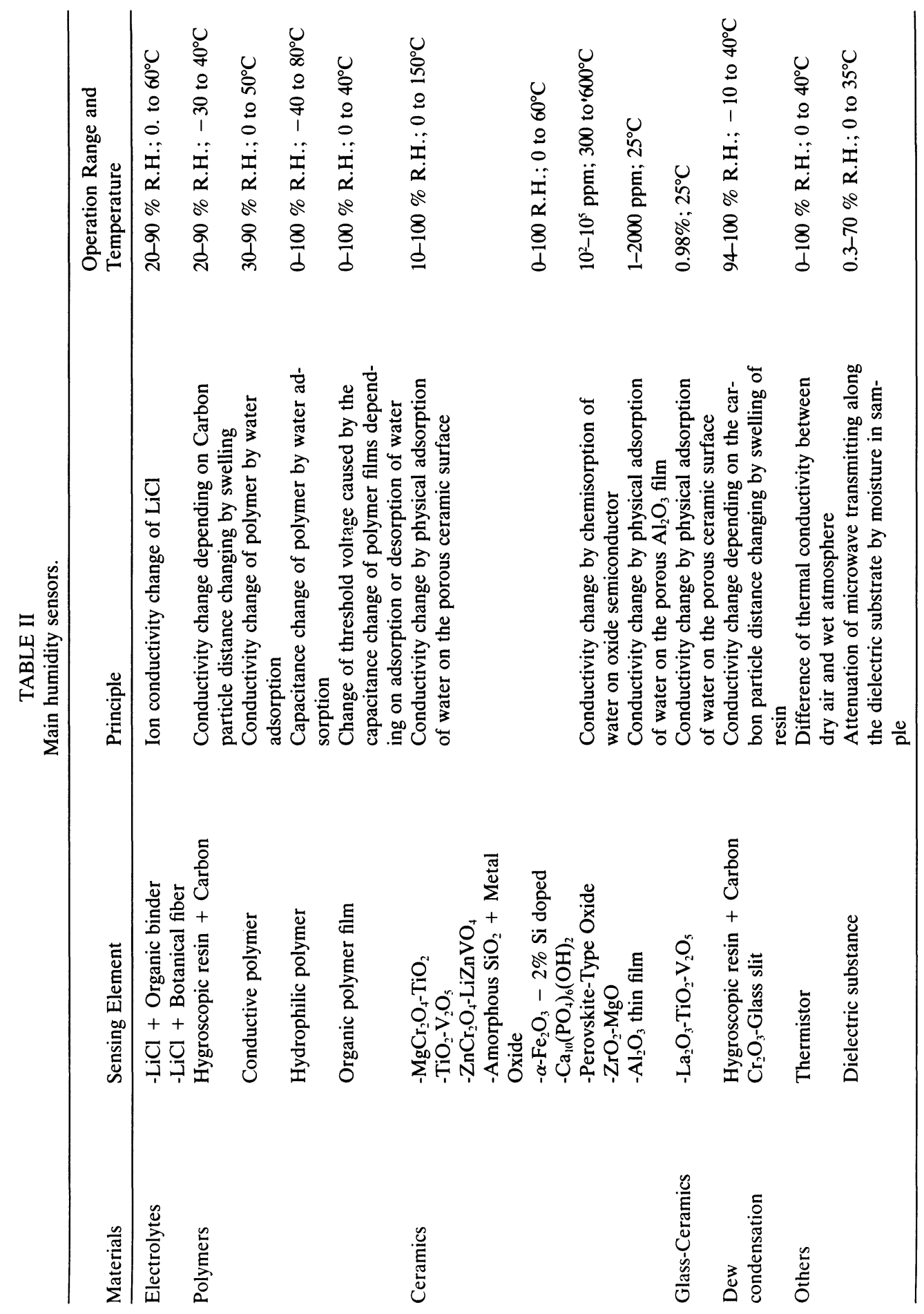


mobile, having restricted freedom of rotation. The succeeding physisorbed layers are ordered in an ice-like structure enrouted to the formation of liquid-like adsorbates that are mobile, free to rotate and to exchange protons.

In ionic-type humidity sensors, the conduction mechanism is mainly due to the displacement of protons between the water molecules. Arai ${ }^{7}$ explains that the conduction mechanism depends on the surface coverage of adsorbed water. Hopping of $\mathrm{H}^{+}$is predominant when the physisorbed $\mathrm{H}_{2} \mathrm{O}$ is absent or very little. When water is present but the coverage of the surface is not complete, $\mathrm{H}_{3} \mathrm{O}^{+}$diffusion dominates. When the $\mathrm{H}_{2} \mathrm{O}$ is abundant, the proton-transfer process dominates. Finally, at higher RH, capillary condensation takes place in the pores according to the Kelvin equation and the conduction mechanism becomes electrolytic ${ }^{2(1)-24}$;

$$
\mathrm{r}_{\mathrm{k}}=\frac{2 \mathrm{M} \gamma}{\rho \mathrm{RT} \ln \mathrm{P}_{\mathrm{s}} / \mathrm{P}}
$$

In the expression, $r_{k}$ is the Kelvin radius of the micropores, $\gamma, \rho$ and $M$ are the surface tension $\left(72,75 \mathrm{dyn} / \mathrm{cm}\right.$ at $\left.20^{\circ} \mathrm{C}\right)$, the density, and the molecular weight of water, $\mathrm{P}$ is vapor partial pressure, and $\mathrm{P}_{\mathrm{s}}$ is the vapor pressure at saturation. The saturation corresponds to the capillary condensation in the pores and, under a constant $\mathbf{P}$ and temperature, takes place in all the pores with radii up to $r_{k}$. The smaller the value of $r_{k}$, the more easily it takes place. The capillary condensation is an important factor in ionic-type humidity sensors.

By taking into account the mechanism of water interaction with metal oxides, it turns out that the humidity sensitivity depends mainly on the microstructure, i.e., the pore size distribution and surface area of the ceramic. These bulk properties are usually controlled by adjusting the particle dimensions of the starting material and the forming and sintering conditions.

Figure 1 shows a drawing representing the typical features of a porous ceramic material. It is composed of grain boundaries formed in the sintering, necks between

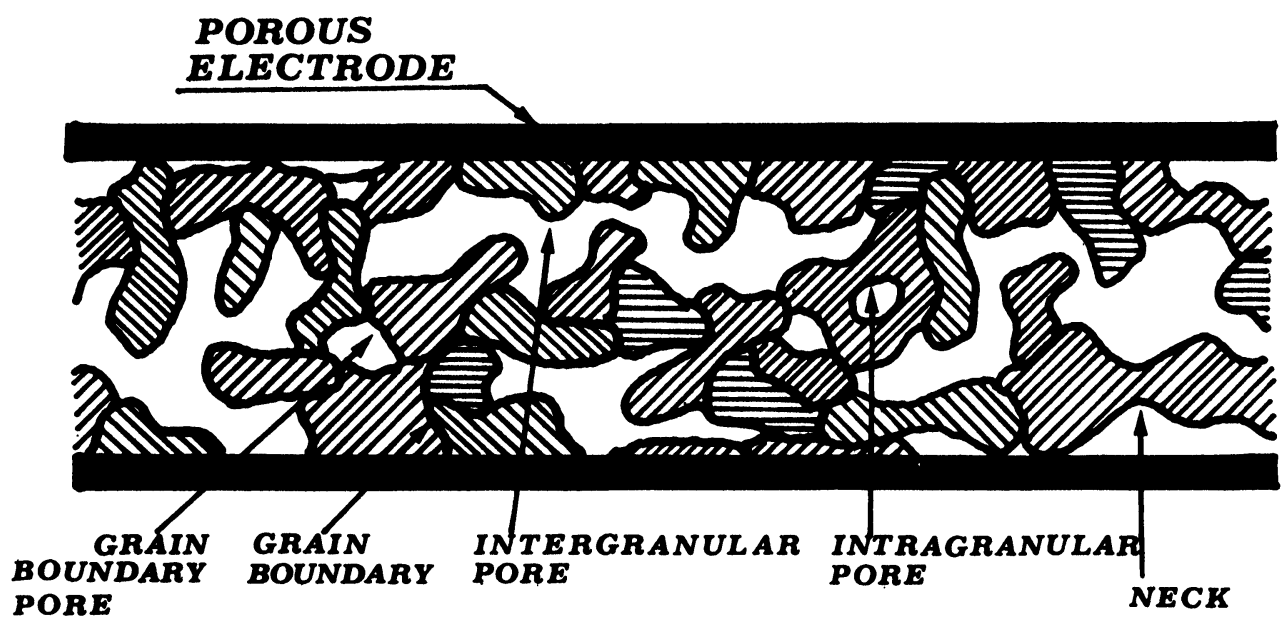

FIGURE 1 Schematic drawing of a typical porous ceramic sensor microstructure. 
the grains, intergranular pores, (open or closed) intragranular pores within the structure of each grain, and grain boundary pores. Another typical characteristic of porous ceramic is the specific surface, which can be as high as $600 \mathrm{~m}^{2} / \mathrm{g}$. Open intragranular and intergranular pores play an important role in the measurement of humidity, since water condenses in the pores with different radii as a function of the RH according to the Kelvin equation.

Figure 2 shows a SEM micrograph of a typical fracture section of $\alpha-\mathrm{Fe}_{2} \mathrm{O}_{3} \mathrm{Si}$ doped ceramic sintered at $950{ }^{\circ} \mathrm{C}$. The ceramic shown in the figure was obtained by isostatically pressing at $100 \mathrm{MPa}$ a $130 \mathrm{~m}^{2} / \mathrm{g}$ specific area acicular $\alpha-\mathrm{Fe}_{2} \mathrm{O}_{3}$ powder, obtained by topotactic decomposition (in high vacuum) of $\alpha-\mathrm{FeOOH}$, with a prior suspension in 3-amino-propyl-trihydroxy-silane solution to yield a 2 weight $\%$ Si. Sintering was performed for 1 hour at $950{ }^{\circ} \mathrm{C}$. The detailed experimental procedure is reported elsewhere. ${ }^{30-32}$

The SEM micrograph highlights the intergranular pores linked so that the structure forms a network of capillary tubes. Intragranular pores (i.e., the pores formed in each particle during the decomposition $\alpha$-FeOOH and remaining after the sintering) are not visible in the figure. They were seen by transmission electron microscopy (TEM) and the pore size distribution, before and after the sintering, was measured by BET liquid $\mathrm{N}_{2}$ adsorption technique ${ }^{8}$.

Figure 3 shows the pore size distribution of the ceramic compact obtained by the liquid $\mathrm{N}_{2}$ adsorption BET method, while Figure 4 shows the pore size distribution obtained by the mercury intrusion technique. The first diagram mainly

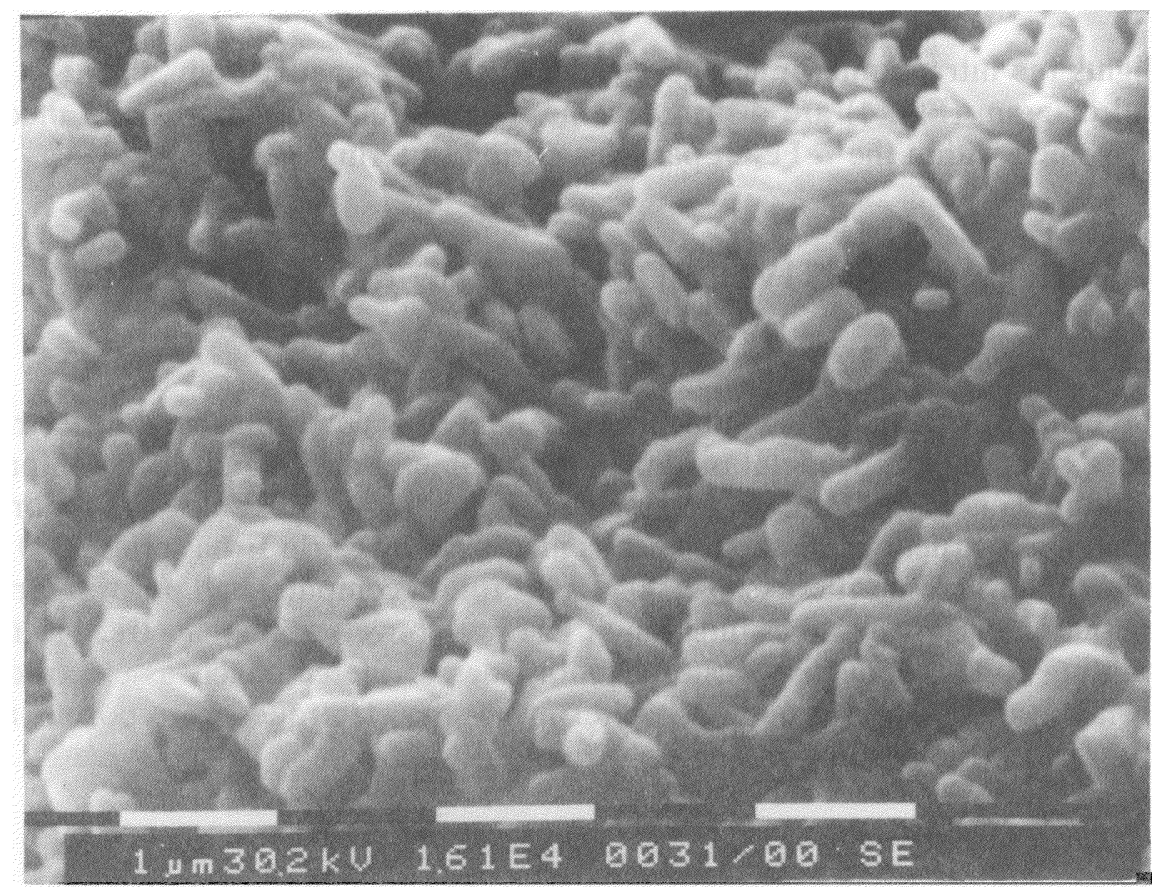

FIGURE 2 SEM micrograph of $950^{\circ} \mathrm{C}$ sintered compact microstructure. 


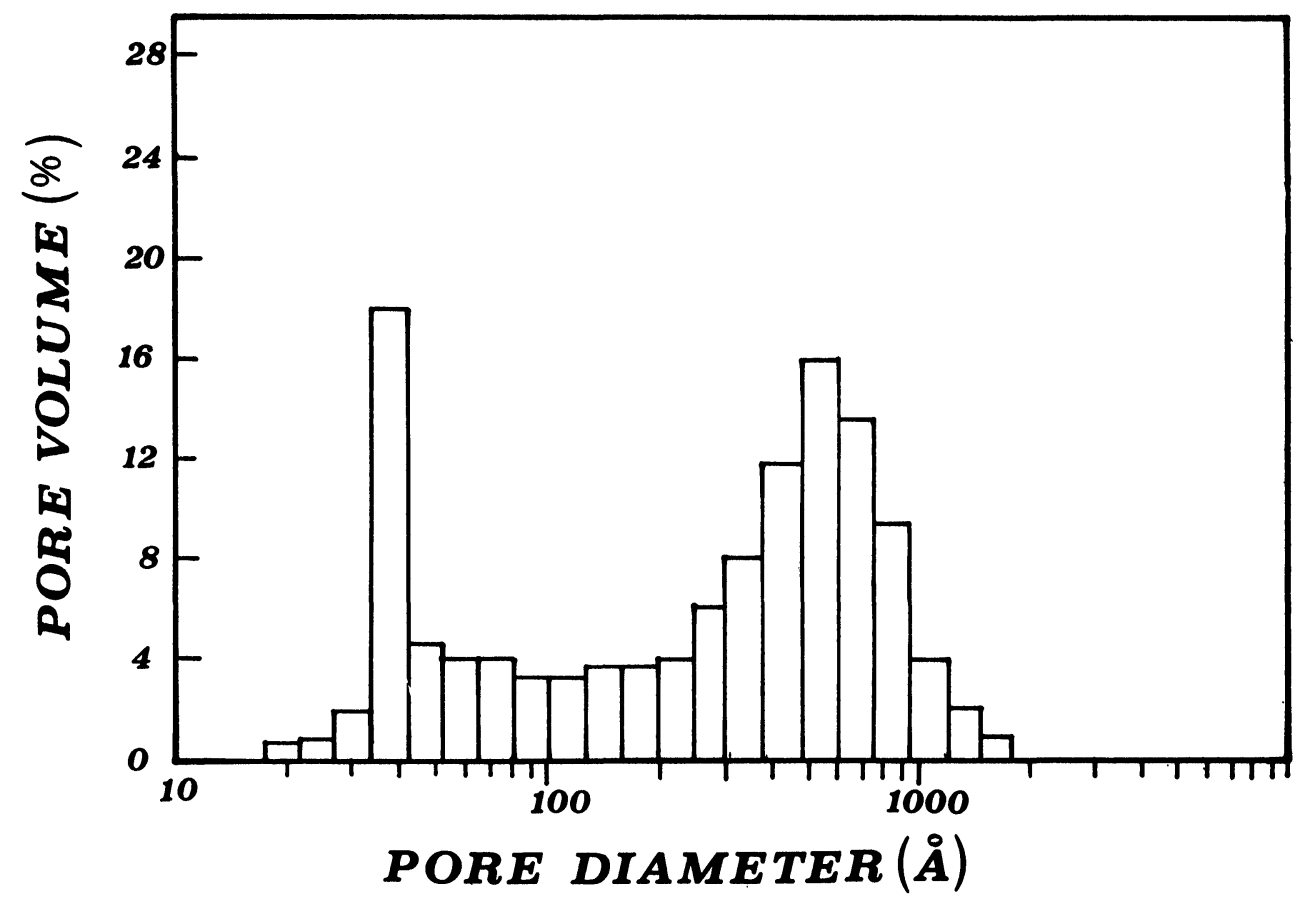

FIGURE $3 \quad \mathrm{~N}_{2}$ adsorption pore size distribution.

highlights the intragranular micropores with diameters smaller than $300 \mathrm{~A}$; in the second diagram (Fig. 4) are distributed the intergranular mesopores and macropores formed within the $\alpha-\mathrm{Fe}_{2} \mathrm{O}_{3}$ particles during sintering.

\section{HUMIDITY SENSITIVITY OF Si-DOPED $\alpha-\mathrm{Fe}_{2} \mathrm{O}_{3}$ SENSOR}

\section{Device Preparation}

With the aim of evaluating the influence of the sintering conditions on the electrical response of microporous metal oxide, $10 \mathrm{~mm}$ diameter and $1 \mathrm{~mm}$ thick compacts were sintered at 850,900 and $950^{\circ} \mathrm{C}$ respectively for 1 hour. In Table 3 are reported the main microstructural characteristics as measured by Carlo Erba series $4000 \mathrm{Hg}$ intrusion and Micromeritics Asap $2000 \mathrm{~N}_{2}$ adsorption computerized porosimetries. The variation of impedance as function of $\mathrm{RH}$ was converted into electrical signals by painting $\mathrm{RuO}_{2}$ conductive paste on both sides of the compact, as electrodes, and firing at $800{ }^{\circ} \mathrm{C}$ for 15 minutes. After firing, the electrodes were porous and did not disturb the adsorption and desorption of water.

\section{The Electrical Response}

The electrical response was measured using the Volt-Amperometric technique by means of a Keithley current amplifier working at $300 \mathrm{~Hz}$ frequency and $1 \mathrm{Vpp}$ 


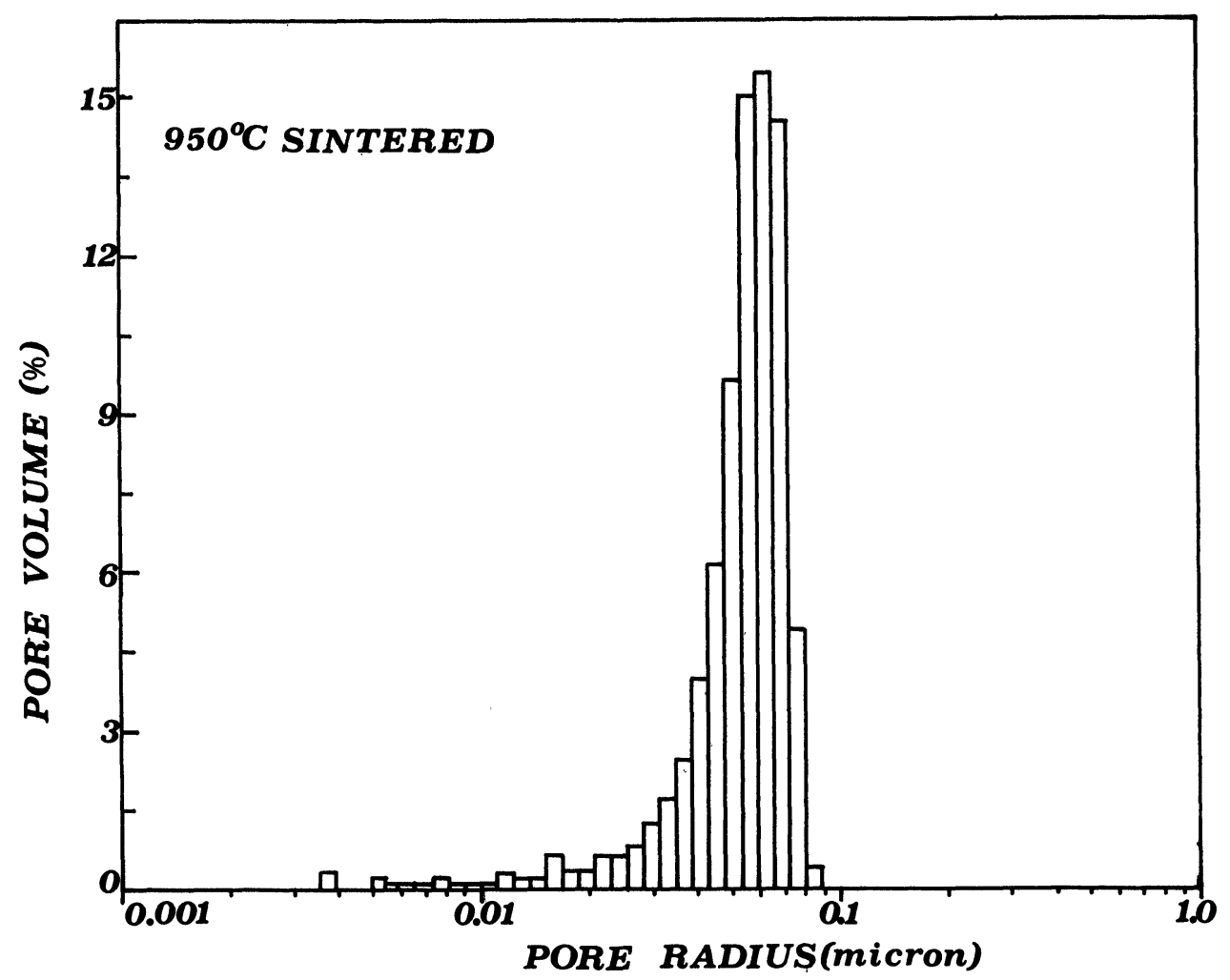

FIGURE $4 \mathrm{Hg}$ intrusion pore size distribution.

voltage. The humidity was varied between 0 and $95 \%$ with an accuracy of $\pm 1 \%$ by mixing dry and water saturated $\mathrm{N}_{2}$ through a MKS model 147 multi-gas controller: By this system, variations of $\mathrm{RH}$ around the sensor were obtained in a few seconds.

TABLE III

Microstructural characteristics of 850,900 , and $950{ }^{\circ} \mathrm{C}$ sintered compacts

\begin{tabular}{|c|c|c|c|}
\hline Sintering Temperature $\left({ }^{\circ} \mathrm{C}\right)$ & 850 & 900 & 950 \\
\hline $\operatorname{Specific~} \operatorname{Area}\left(\mathrm{m}^{2} / \mathrm{g}\right)[*]$ & 13.72 & 10.57 & 7.22 \\
\hline $\begin{array}{l}\text { Cumulative Pore Volume[*] } \\
\text { in the } 10-300 \AA\left(\mathrm{cm}^{3} / \mathrm{g}\right)\end{array}$ & $6.70 \cdot 10^{-2}$ & $5.62 \cdot 10^{-2}$ & $2.93 \cdot 10^{-2}$ \\
\hline $\begin{array}{l}\text { Average Pore Size }\left[{ }^{*}\right] \\
\text { in the } 10-300 \AA(\AA)\end{array}$ & 25.3 & 35.3 & 47.2 \\
\hline $\begin{array}{l}\text { Cumulative Pore }\left[{ }^{* *}\right] \\
\text { in the } 300-10000 \AA\left(\mathrm{cm}^{3} / \mathrm{g}\right)\end{array}$ & 0.285 & 0.252 & 0.220 \\
\hline $\begin{array}{l}\text { Average Pore Size }\left[{ }^{*}\right] \\
\text { in the } 300-10000 \AA(\mu \mathrm{m})\end{array}$ & 0.053 & 0.062 & 0.075 \\
\hline Porosity $\%\left[{ }^{* *}\right]$ & 60.72 & 56.84 & 54.03 \\
\hline Density $\mathrm{g} / \mathrm{cm}^{3}[* *]$ & 2.13 & 2.25 & 2.45 \\
\hline
\end{tabular}

[*] Measured by $\mathrm{N}_{2}$ Adsorption

$\left[{ }^{* *}\right]$ Measured by $\mathrm{Hg}$ Intrusion 


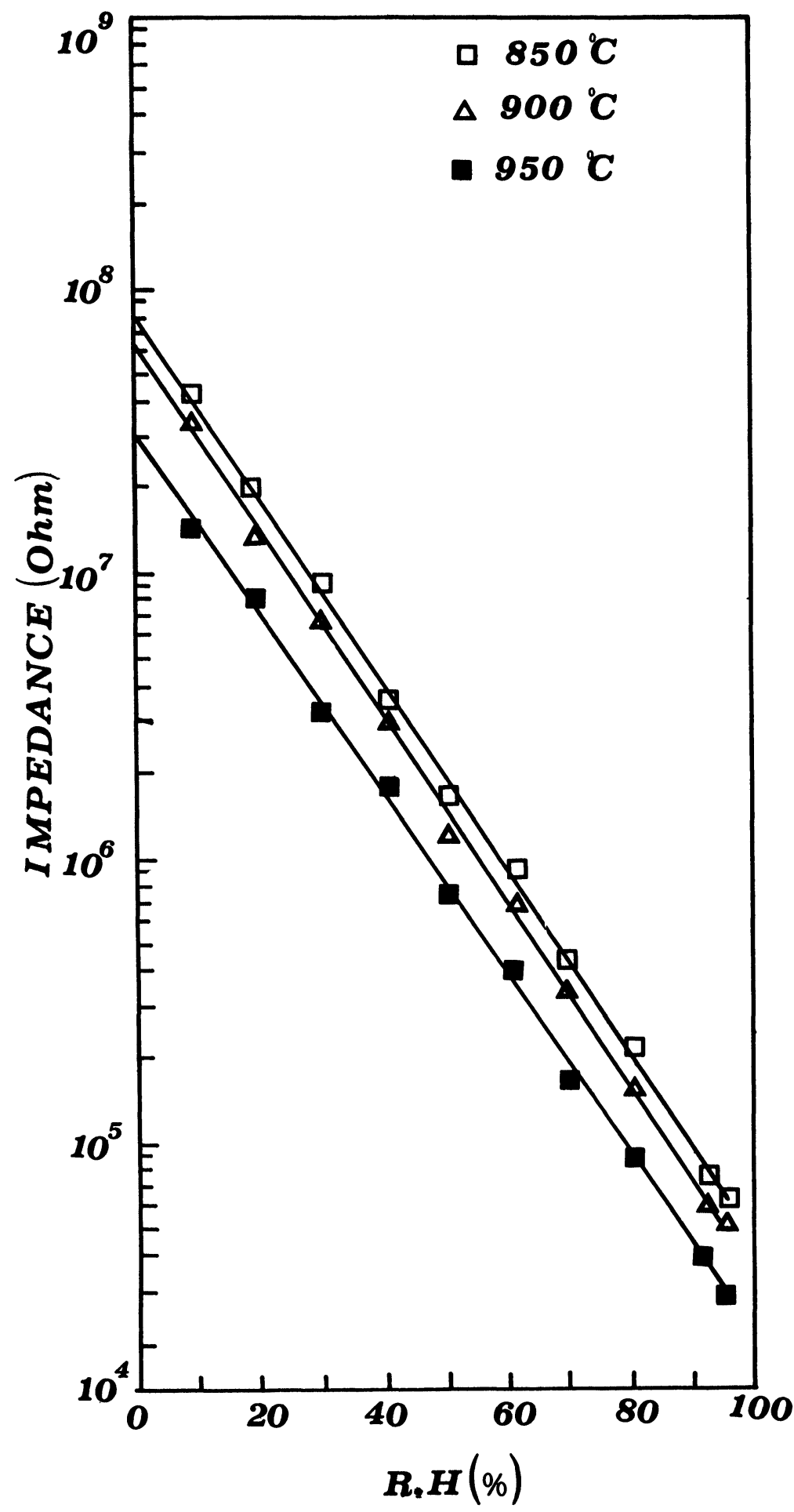

FIGURE 5 Humidity sensitivity of sintered compacts. 
Figure 5 shows the typical plot of the impedance variation (ohm in logarithmic scale) as a function of $\mathrm{RH}$, evaluated for the compacts sintered at different temperatures.

- The response of the $\alpha-\mathrm{Fe}_{2} \mathrm{O}_{3}$ to the variation of $\mathrm{RH}$ is linear in the whole investigated range, allowing for simple circuit design when converting the electrical signal into the RH value.

- The intrinsic impedance (i.e., the impedance measured at $0 \% \mathrm{RH}$ ) is in the order of magnitude of $1 \mathrm{M} \Omega$ and permits simple and accurate determination at very low RH values. It decreases from 850 to $950^{\circ} \mathrm{C}$ sintering as the grain boundaries extension increases.

- The three decades impedance magnitude variation allows accurate determination of the signal variation due to small changes in $\mathrm{RH}$.

- Sintering at higher temperature $\left(1000-1100{ }^{\circ} \mathrm{C}\right)^{31.32}$ results in poor humidity sensitivity in the lower RH values $(0-40 \%)$ because of the coalescence of micropores due to the thermal treatment. The better humidity sensitivity obtained for the $850-950{ }^{\circ} \mathrm{C}$ sintering is explained in terms of a favorable pore size distribution around the condensation critical radius.

In defining the properties of a humidity sensor, the evaluation of the response time to the variation of RH acquires particular importance. In bulk sensors, the response time is controlled by the diffusion rate of the water vapor through the pores therefore depends on the forming and sintering conditions.

Figure 6 depicts the response time of the $950{ }^{\circ} \mathrm{C}$ sintering during adsorption and desorption cycles in the $0-60 \% \mathrm{RH}$ range at different water vapor flow rates. The residence times, as calculated by the geometry of the cell, are 6.2, 4.5 and 3.7 seconds respectively. From the figure it turns out that the higher the water vapor flow rate the shorter the response time. While the adsorption is faster than the desorption, both processes are very quick.

\section{THE CALIBRATION PROCEDURE USED TO CHARACTERIZE THE $\alpha$ - $\mathrm{Fe}_{2} \mathrm{O}_{3}$ HUMIDITY SENSOR}

\section{Hysteresis $(H)$ and Drift $(d)$}

In evaluating the properties of a humidity sensor, the hysteresis $(\mathrm{H})$ and drift $(\mathrm{d})$ must be carefully characterized, because they represent a consistent part of the final error associated with the RH measurement. Generally, this error is not constant but is influenced by the operating conditions of the sensor. The hysteresis can be defined as the difference in the recording signal measured when carrying out a full cycle of adsorption and desorption, for example from 11 to 97 back to $11 \% \mathrm{RH}$. The drift is the difference between the asymptotic signal value at saturation (holding the sensor in saturation conditions for several hours) and the value measured after a shorted time, for example one hour at saturation.

In order to carry out accurate characterization of these parameters, $\mathrm{RH}$ standards are needed. The easiest way is to use saturated salt solutions such as $\mathrm{LiCl}, \mathrm{NaCl}$, $\mathrm{K}_{2} \mathrm{SO}_{4}$ that, at a certain temperature, have a constant equilibrium water partial 


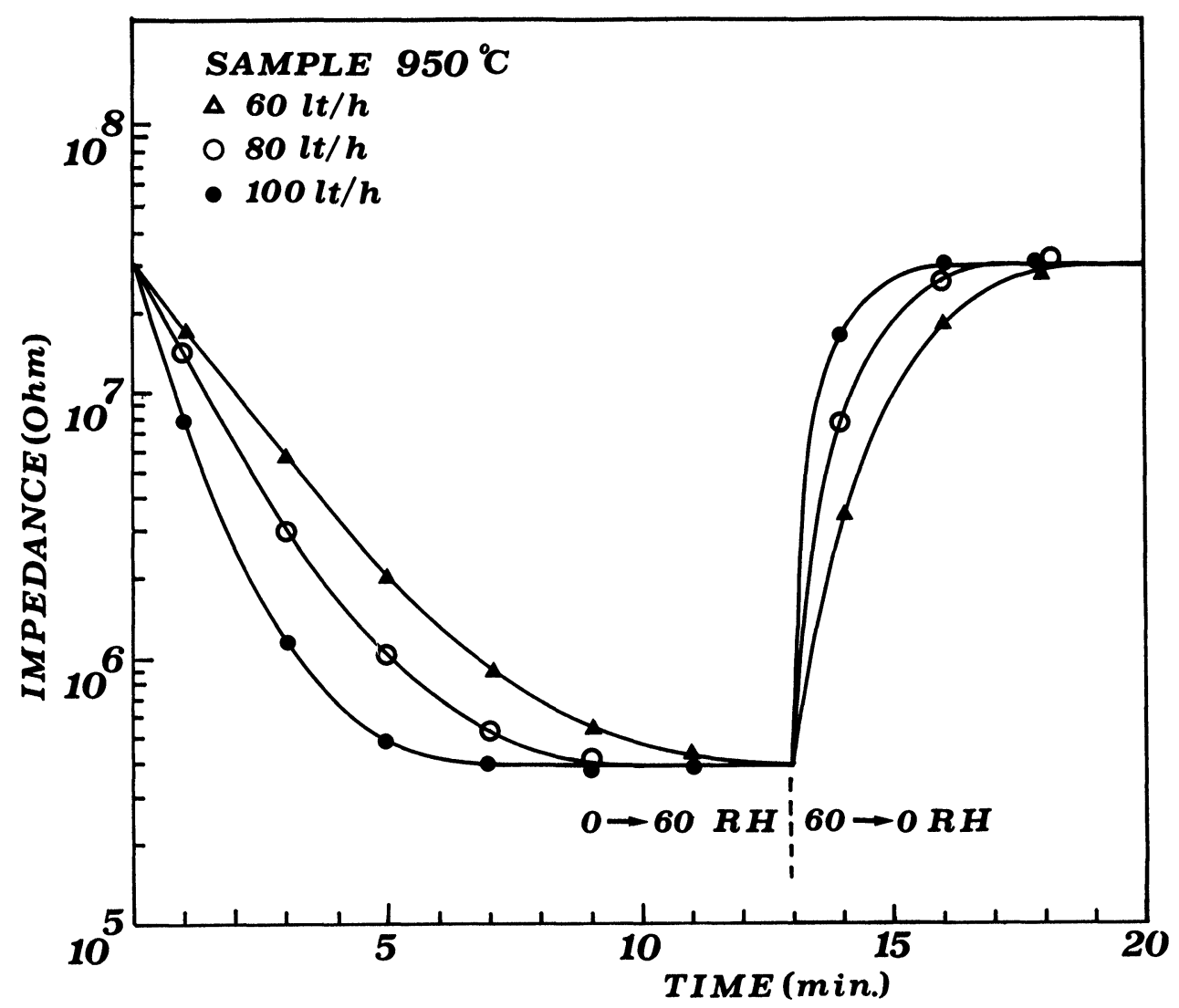

FIGURE 6 Response time of $950{ }^{\circ} \mathrm{C}$ sintered compact under adsorption and desorption cycle.

pressure and can furnish a fixed and stable value of RH. Moreover, the dependence on temperature of $\mathrm{RH}$ is very small. In this way, $11 \%, 75 \%$ and $97 \% \mathrm{RH}$ were obtained by using $\mathrm{LiCl}, \mathrm{NaCl}$ and $\mathrm{K}_{2} \mathrm{SO}_{4}$ saturated solid solution at $30{ }^{\circ} \mathrm{C}^{33}$.

A typical run, shown in Fig. 7, was carried out by placing the sensor for $1 \mathrm{~h}$ at $11 \% \mathrm{RH}$ and the impedance recorded at 15 min interval; then rapidly moving to the $75 \% \mathrm{RH}$ and to $97 \%$ for one hour respectively. The desorption was carried out by using the solutions in the opposite way, obtaining the evaluation of the hysteresis relative to each solution, $\mathrm{H}_{1}=1 \%$ and $\mathrm{H}_{3}=3 \%$. Leaving the sensor at $97 \% \mathrm{RH}$ overnight, at $16 \mathrm{~h}$ the drift can be evaluated. At $75 \% \mathrm{RH}$ the sensor shows an hysteresis $\mathrm{H}_{2}=4 \%$ and at $11 \% \mathrm{RH}$ an $\mathrm{H}_{4}=3 \%$.

\section{Aging}

The aging of a sensor is caused by its prolonged use at different temperatures and environments. The aging of our sensor was simulated by means of a climatic chamber carrying out a 21 day cycle in which the sensor was submitted to daily variations of temperature between 30 and $42{ }^{\circ} \mathrm{C}$ and $\mathrm{RH}$ between 45 and $95 \%$, as described 


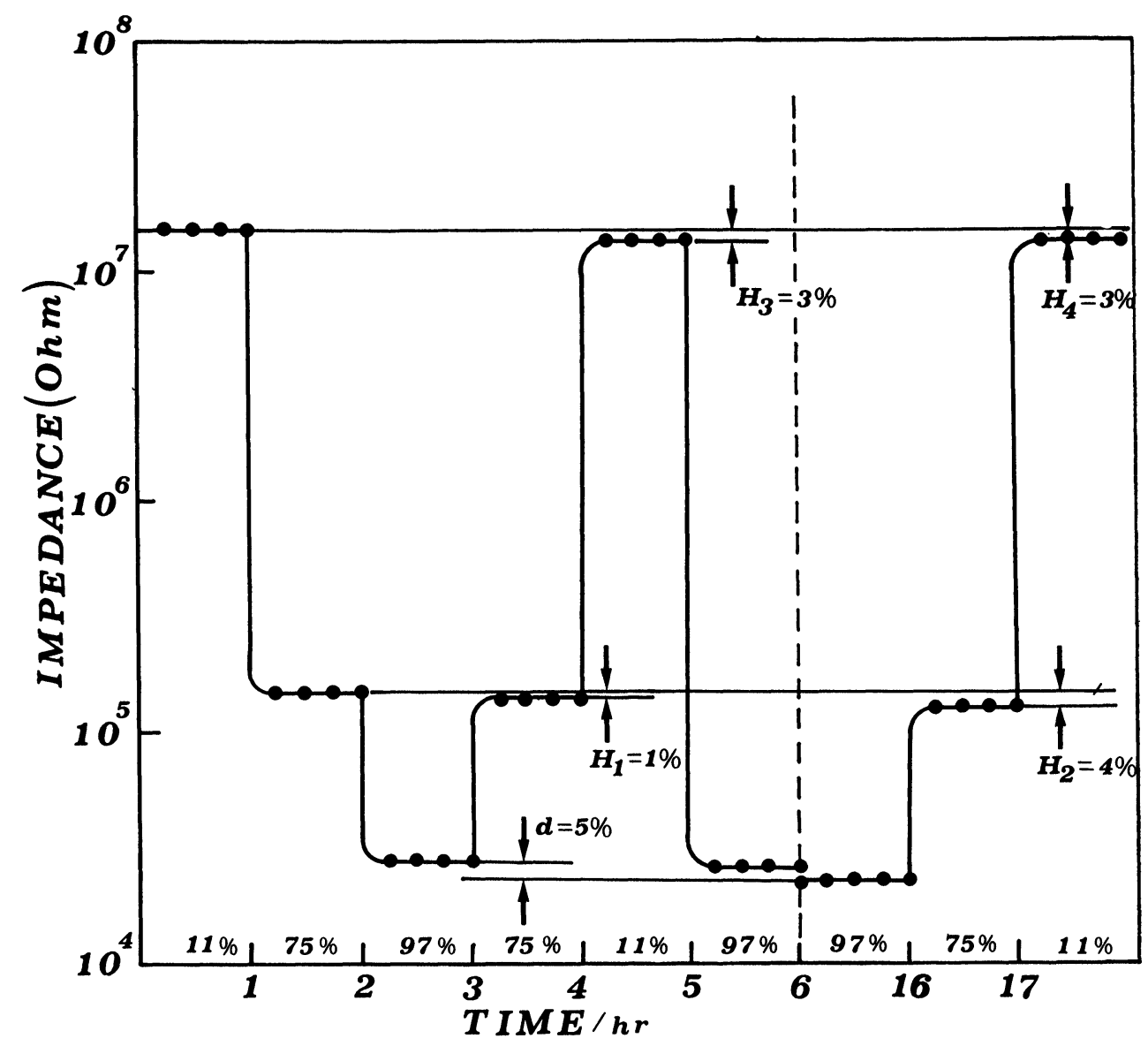

FIGURE 7 The response of $950^{\circ} \mathrm{C}$ above saturated salt solution.

in Fig. 8. After each aging cycle, the impedance was measured at $11 \%, 75 \%$ and $97 \%$ by means of the above mentioned saturated solutions.

Eight cycles were carried out on the same sensor, for a total aging time of 168 days. The results of the impedance are reported in Fig. 9. The uncertainties associated to each $11 \%, 75 \%$ and $97 \% \mathrm{RH}$ are an overall estimation of the error associated with the impedance measurement, considering the hysteresis and drift evaluated according to the previously reported procedure. The average uncertainty on $\mathrm{RH}$ measurement is estimated as $4 \%$.

\section{Temperature Dependence}

The evaluation of the temperature dependence of the recorded signal is particularly important in ionic humidity sensors since the physisorption and capillary condensation of water molecules on the ceramic surface and pores are greatly influenced by this parameter. The sensor was calibrated in a climatic chamber between 25 and $95{ }^{\circ} \mathrm{C}$. The results are showed in Fig. 10. 


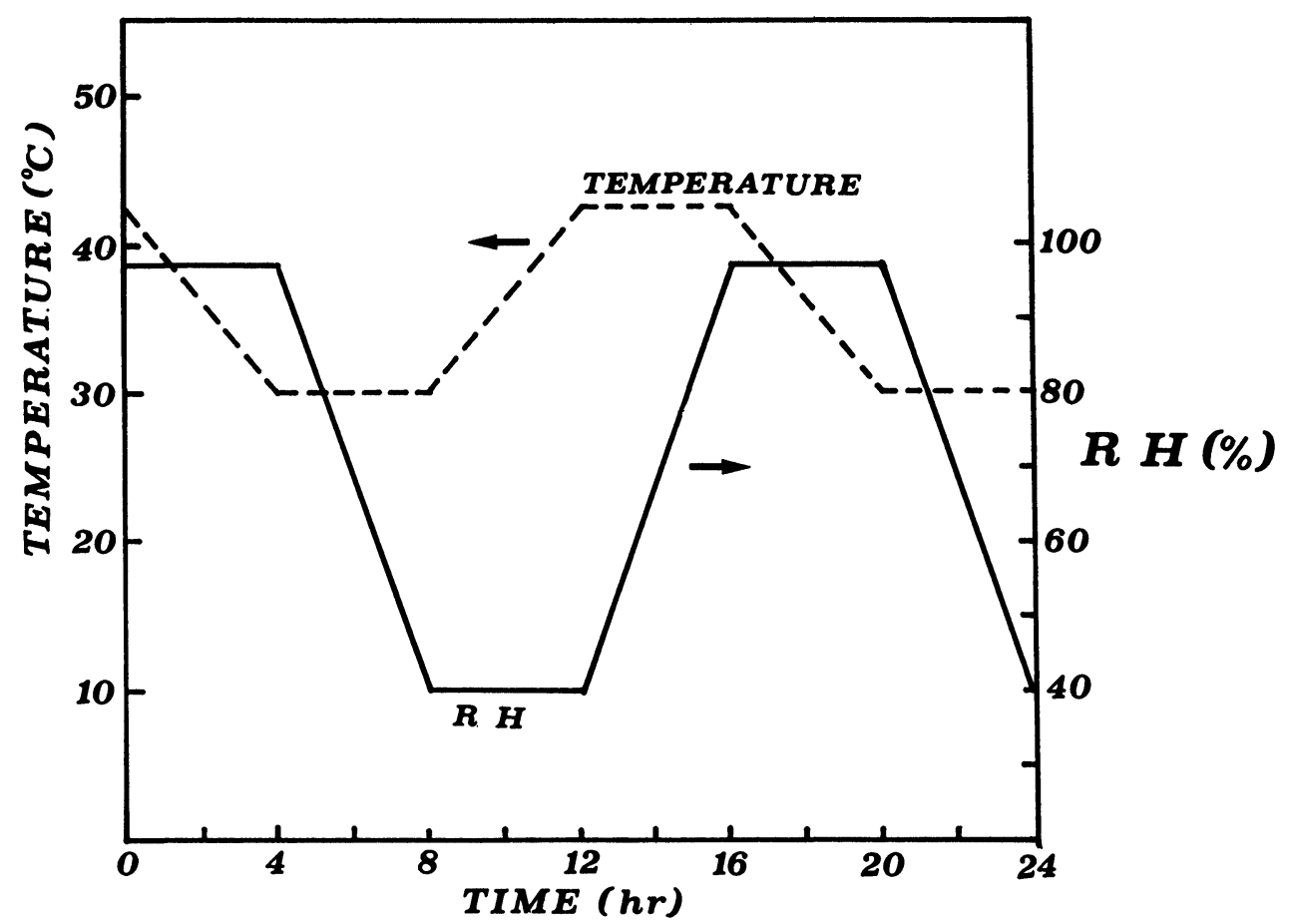

FIGURE 8 Temperature and RH variation during one day cycle in climatic test chamber.

\section{CARBON MONO-OXIDE SENSITIVITY}

As previously described, ceramic sensors exhibit high sensitivity to reducing gases when activated at high temperature, usually between 300 and $450{ }^{\circ} \mathrm{C}$. At the moment, studies are being carried out in our laboratory to develop a multifunction ceramic sensor based on Si-doped $\alpha-\mathrm{Fe}_{2} \mathrm{O}_{3}$, which can detect humidity in the $0-100$ ${ }^{\circ} \mathrm{C}$ and $\mathrm{CO}$ in the $350-450{ }^{\circ} \mathrm{C}$ ranges without cross-talk of the electrical signals.

Preliminary tests of $\mathrm{CO}$ sensitivity were carried out on three compacts (undoped, $2 \%$ and $4 \%$ Si-doped) sintered at $900{ }^{\circ} \mathrm{C}$ for $1 \mathrm{~h}$. The results, plotted as $\Delta \mathrm{R} / \mathrm{R} \%$ as a function of the activation temperature of the sensor, are shown in Fig. 11. The tests were carried out by heating the sensor at $100{ }^{\circ} \mathrm{C}$ steps in the $0-500{ }^{\circ} \mathrm{C}$ range. At each temperature, the resistence, $R$ in ohm, was measured in dry air and in $900 \mathrm{ppm}$ of a CO-air mixture. The $\mathrm{R}_{\text {air }}-\mathrm{R}_{\mathrm{CO}} / \mathrm{R}_{\text {air }}=\Delta \mathrm{R} / \mathrm{R}$ was plotted as function of the activation temperature. The $\alpha-\mathrm{Fe}_{2} \mathrm{O}_{3}$ sensor showed the highest sensitivity to $\mathrm{CO}$ at $400{ }^{\circ} \mathrm{C}$ with $60 \%$ variation of resistence. The sensitivity to other reducing gases such as $\mathrm{SO}_{2}$, hydrocarbons, and smoke is also investigated to fully characterize the selectivity of the sensor.

\section{REALIZATION OF A HUMIDITY MONITORING DEVICE}

The satisfactory characteristics shown in the laboratory tests by the Si-doped $\alpha$ $\mathrm{Fe}_{2} \mathrm{O}_{3}$ sensor, allows the realization of dedicated, low-cost, electronic circuits for 


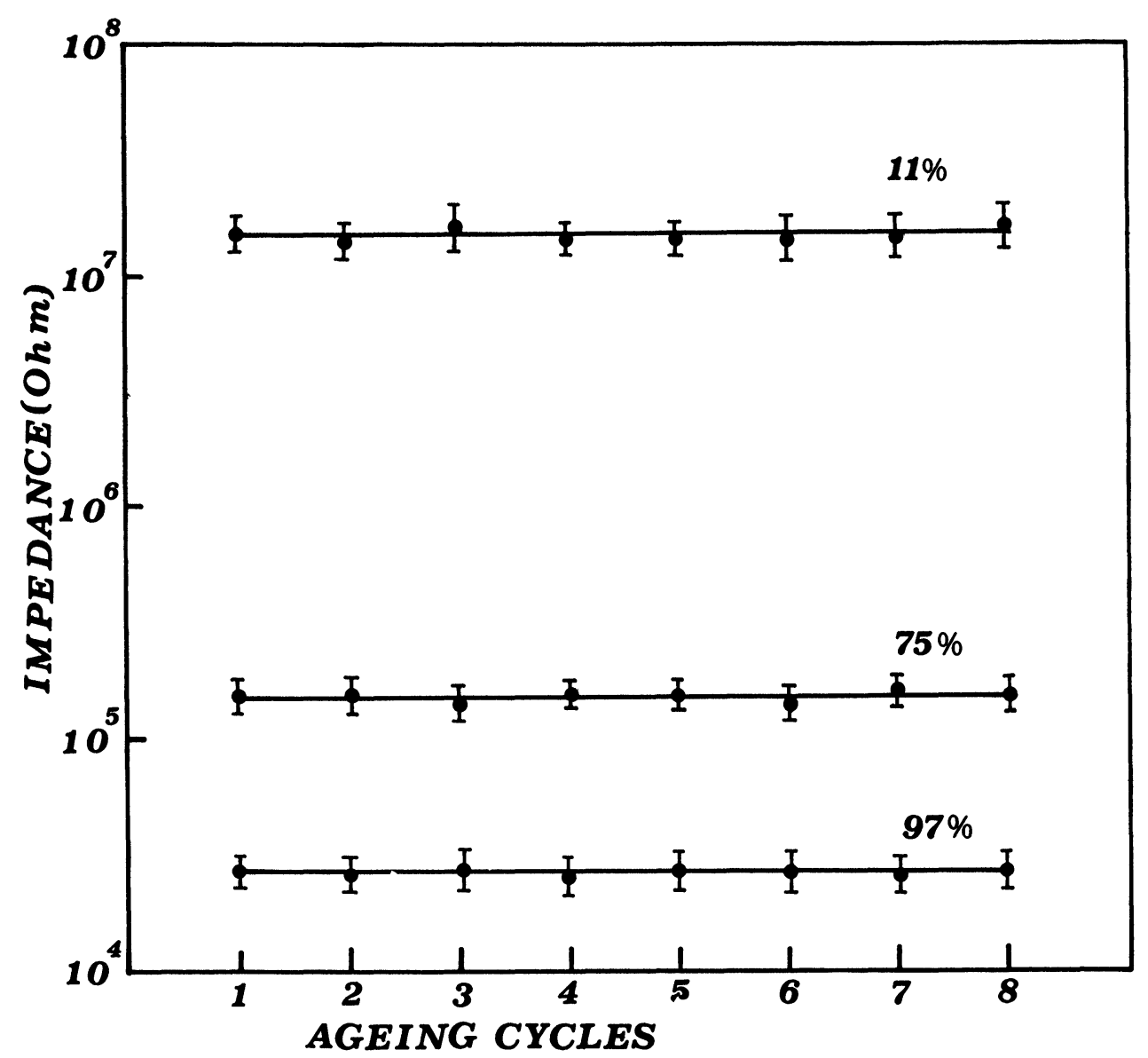

FIGURE 9 Impedance values in saturated salt solution after aging cycles (21 days each).

humidity monitoring. An electronic circuit prototype for humidity measurement has been, buildup taking into account the experimentally determined temperature dependency. The electronic equipment was set up with a commercial, low-cost, integrated circuit and based on the direct measurement of the sensor impedance magnitude.

In Fig. 12, a block scheme of the electronic equipment prototype is shown. The impedance magnitude of the sensor is measured by the volt-amperometric method: a Wien bridge harmonic voltage generator (Osc) and a sophisticated current to voltage converter (I/V Conv.) was utilized. The peak value of the output voltage of the I/V Conv. was made proportional to the impedance magnitude of the sensor. A logarithmic amplifier ( $\log$. Amp) was utilized for the linearization of the response when it changed with humidity. The temperature compensation of the humidity measurement was obtained by an electronic integrated temperature sensor with linear response in the $0-100^{\circ} \mathrm{C}$ range, an amplifier stage for signal adjustment, and an algebraic summing amplifier $(\Sigma)$. The algebraic summing amplifier com- 


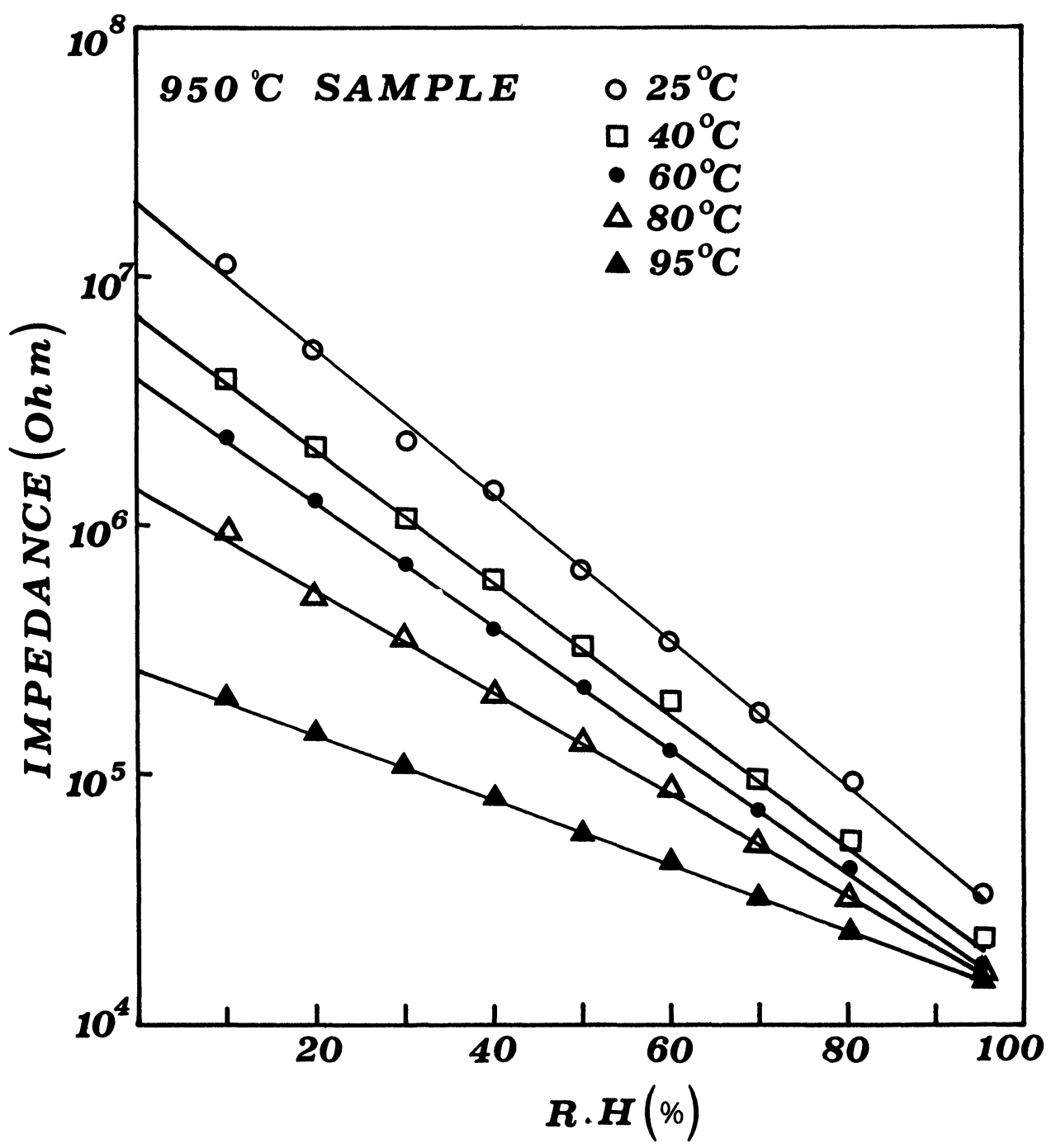

FIGURE 10 Temperature dependance of the impedance as a function of the RH.

pensated the impedance signal of the humidity sensor with the temperature signal, according to the experimental calibration shown in Fig. 10. The environmentmeasured RH value is shown by a stack of twenty Light Emitter Diodes (LED), which gave the value of the humidity in the range $0-100 \% \mathrm{RH}$, with a $5 \%$ step.

\section{ACKNOWLEDGEMENTS}

The Authors are grateful to the Consiglio Nazionale delle Ricerche (C.N.R.) through the "Progetto Finalizzato Materiali Speciali per Tecnologie Avanzate" for the financial support to the research programme.

The Author wish to thank the Department of Chemical Engineering and Materials of the University of Cagliari for the collaboration in obtaining part of the experimental results reported in this paper. 


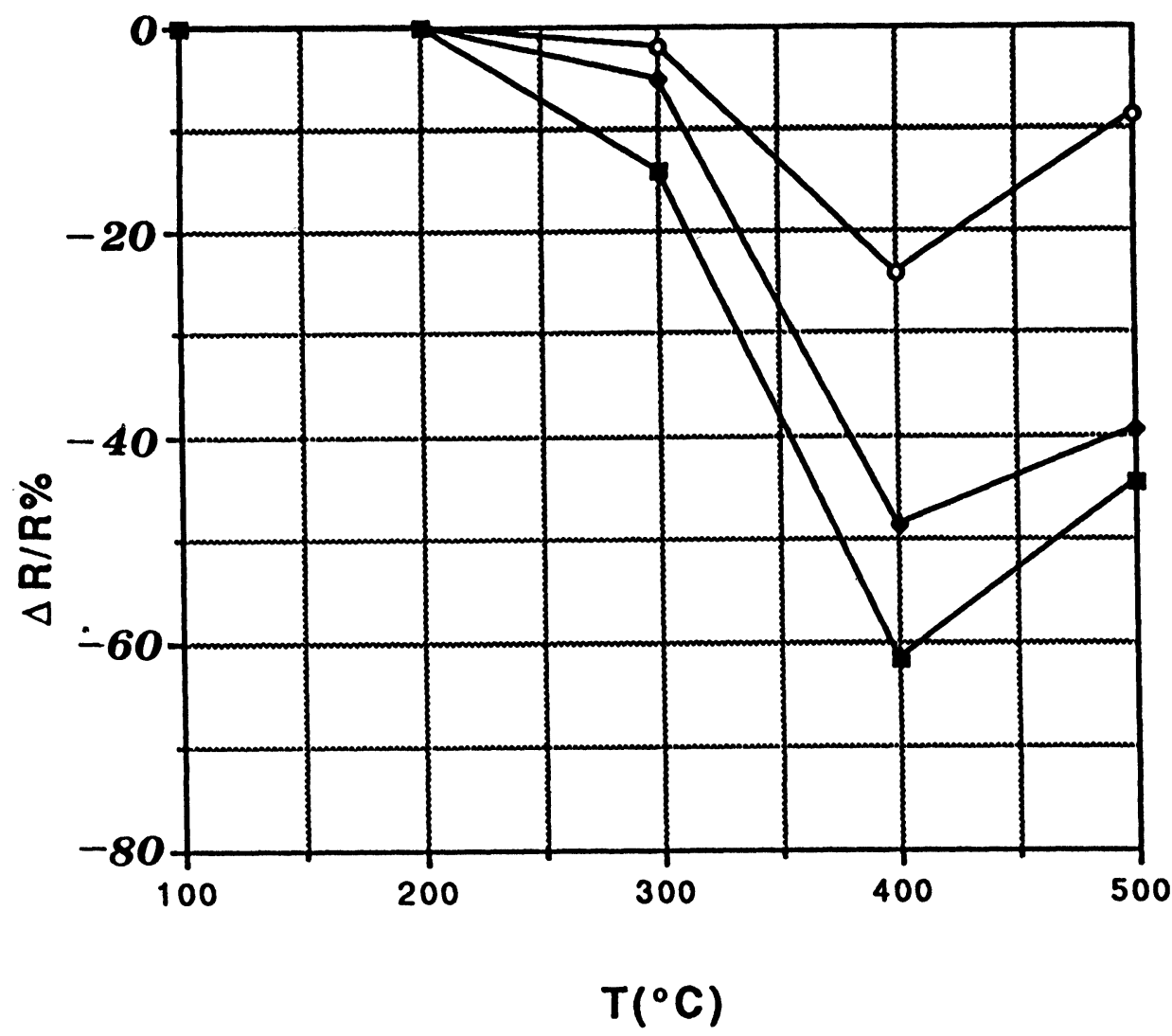

FIGURE 11 Carbon mono-oxide sensitivity for $900{ }^{\circ} \mathrm{C}$ sintered compacts: $\bigcirc$ undoped; $\diamond 2 \% \mathrm{Si}$ doped; $\square 4 \%$ Si-doped.

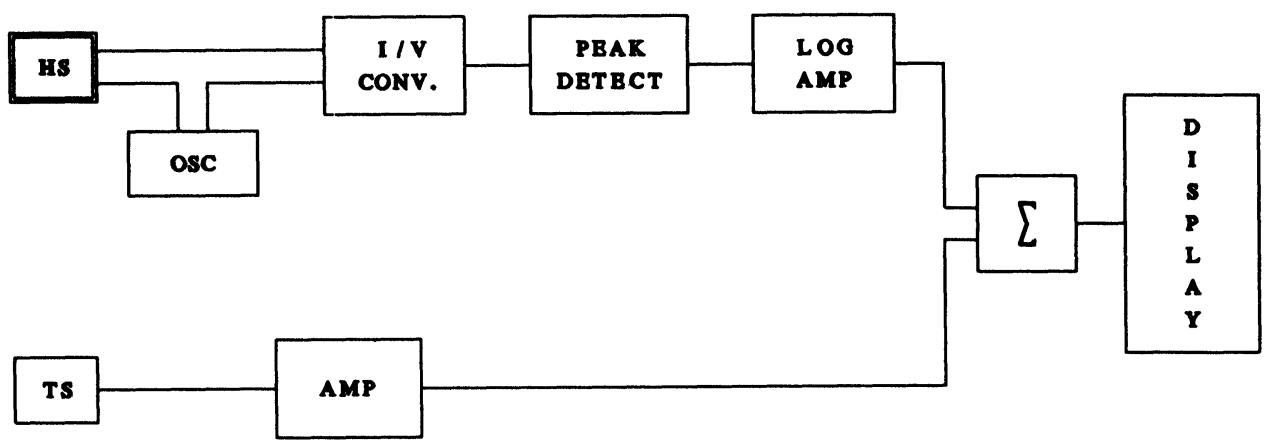

FIGURE 12 Block scheme of the humidity monitoring prototype. HS: Humidity Sensor; TS: Temperature Sensor; OSC: Harmonic Oscillator; I/V CONV.: Current to Voltage Converter; LOG AMP: Logarithmic Amplifier; AMP: Amplifier; $\Sigma$ : Algebraic Summing Amplifier; DISPLAY: Display System. 


\section{BIBLIOGRAPHY}

1. B.M. Kulwicki, “Ceramic sensors and transducers.”, J. Phys. Chem. Solids, 45, 1015-1031, (1984).

2. W. Heywang and H. Thomann, "Positive temperature coefficient resistors.", in Electronic Ceramics, edited by B.C.H. Steele, Elsevier, Amsterdam, 29-47, 1991.

3. T. Nitta, Z. Terada and S. Hayakawa, U.S. patent no. 4086556 (Apr. 25, 1978).

4. N. Yamazoe and Y. Shimizu, "Humidity sensors: Principles and application.", Sensors and Actuators, 10, 379-398, (1986).

5. T. Nitta, "Development and application of Ceramic Humidity Sensor.", in Chemical Sensor Technology, vol. 1, edited by T. Seiyama, Elsevier, Amsterdam, 57-78, 1988.

6. T. Yamamoto and K. Murakami, "Humidity sensor using $\mathrm{TiO}_{2}-\mathrm{SnO}_{2}$ ceramics.", in Chemical Sensor Technology, vol. 2, edited by T. Seiyama, Elsevier, Amsterdam, 133-149, 1989.

7. H. Arai, T. Seiyama, "Humidity Sensors.", in Sensor a Comprehensive Survey edited by W. Gopel, VCH Weinheim 1992, vol. 3, part II, 982-1012, 1992.

8. C. Cantalini and M. Pelino, "Microstructure and Humidity-Sensitive characteristics of $\alpha$ - $\mathrm{Fe}_{2} \mathrm{O}_{3}$ ceramic sensor", J. Am. Ceram. Soc., 75, (3), 546-551, (1992).

9. S.R. Morrison, "Semiconductor gas sensors.", Sensors and Actuators, 2, 329-341, (1982).

10. J.F. McAleer, P.T. Moseley, J.O.W. Norris and D.E. Williams, "Tin dioxide gas sensors.", J. Chem: Soc. Faraday Trans. 1, 83, 1323-1346, (1987).

11. T. Nakahara and H. Koda, "Tin dioxide gas sensor: a new approach to odor sensing.", in Chemical Sensor Technology, edited by N. Yamazoe, Elsevier, Amsterdam, 19-32, 1991.

12. S. Matsuura, "New development and application of gas sensor in Japan.", Fourth International Meeting on Chemical Sensors, Tokyo, Japan, 6-11, 1992.

13. F. McAleer, P.T. Moseley, J.O.W. Norris, D.E. Williams and B.C. Tolfield, "Tin dioxide gas sensors", J. Chem: Soc. Faraday Trans. 1, 82, 441-457, (1988).

14. D. Kohl, "The role of noble metals in the chemistry of solid state gas sensors.", Sensors and Actuators, B1, 158-165, (1990).

15. M. Prudenziati, "Thick film Technology.", Sensors and Actuators A, 227-234, (1991).

16. F. Forlani, "Film spesso nei sensori chimici e biochimici.", Elettronica Oggi, 145, 62-69, (1992).

17. T. Suzuki, T. Yamazaki, K. Takahashi, T. Kageyama and H. Oda, "Ion-beam sputtering apparatus for deposition of multilayered films." J. Mat. Sci. Lett., 7, 79-80, (1988).

18. R. Lalauze, P. Breuil and C. Pijolat, "Thin films for gas sensors.", Sensors and Actuators B, 3, 175-182, (1991).

19. H.T. Sun, T. Cheng, X. Yao, W. Wlodarski, "Humidity sensors of Sol-gel-derived silica coating on quartz crystal." Fourth International Meeting on Chemical Sensors, 13-17 September, Tokyo, Japan, 124-127, 1992.

20. T. Morimoto, M. Nagao and F. Tokuda, "The relation between the amounts of chemisorbed and physisorbed water on metal oxides.", J. Phys. Chem., 73, 243-248, (1969).

21. E. McCafferty and C. Zettlemoyer, "Adsorption of water vapour on $\alpha-\mathrm{Fe}_{2} \mathrm{O}_{3}$.", Discuss. Faraday Soc., 3, 239-255, (1971).

22. Y. Shimizu, H. Arai and T. Seiyama, "Theoretical studies on the impedance-humidity characteristics of ceramic humidity sensors.", Sensors and Actuators, 7, 11-22, (1985).

23. J.H. de Bore, "The shape of capillaries, the structure and properties of porous materials.", Butterworth, London, 68-94, 1958.

24. Y. Morioka and J. Kobayashy, "Sorption Hysteresis and network structure of pores in porous substances, part. 1.”, Nippon Kagaku Kaishi, 153-157, (1979).

25. U. Weimar, S. Vaihinger, K.D. Schierbaum and W. Gopel, "Multicomponent analysis in chemical sensing.", in Chemical Sensor Technology vol. 3, edited by N. Yamazoe, Elsevier, Amsterdam, 51-116, 1991.

26. A.L. Harmer, "European research on advanced sensors.", in Sensors Technology systems and applications, edited by K.T.V. Grattan, Adam Hilger, Bristol, 475-491, 1991.

27. Y. Yamada, "Lithium cloride humidity sensor.", Denshi-Gijutsu, 21, 26-30, (1979).

28. H. Grange and G. Delapierre, "Polymer-based capacitive Hygrometers.", in Chemical Sensor Technology vol. 3, edited by N. Yamazoe, Elsevier, Amsterdam, 147-162, 1991.

29. Y. Shimizu, M. Shimabukuro, H. Arai and T. Seiyama, "Humidity sensitive characteristics of $\mathrm{La}^{3+}$-doped and undoped $\mathrm{SrSnO}_{3}$.", J. Electrochem. Soc., 136, 1206-1210, (1989). 
30. M. Pelino, L. Toro, M. Petroni, A. Florindi and C. Cantalini, "Study of kinetics of decomposition of $\alpha$-goethite in vacuo and pore structure of product particles.", J. Mat. Sci., 24, 409-412, (1989).

31. M. Pelino, C. Colella, C. Cantalini, M. Faccio, G. Ferri and A. D'Amico, "Microstructure and electrical properties of an $\alpha$-hematite humidity sensor.", Sensors and Actuators B, 7, 464-469, (1992).

32. C. Cantalini, M. Faccio, G. Ferri and M. Pelino, "Microstructure and electrical properties of Sidoped $\alpha-\mathrm{Fe}_{2} \mathrm{O}_{3}$ humidity sensor.", Sensors and Actuators B, 293-298, (1993).

33. L. Greenspan, "Humidity fixed points of binary saturated aqueous solutions.", J. Research National Bureau of Standards, vol. 81 A, 89-96 (1977). 

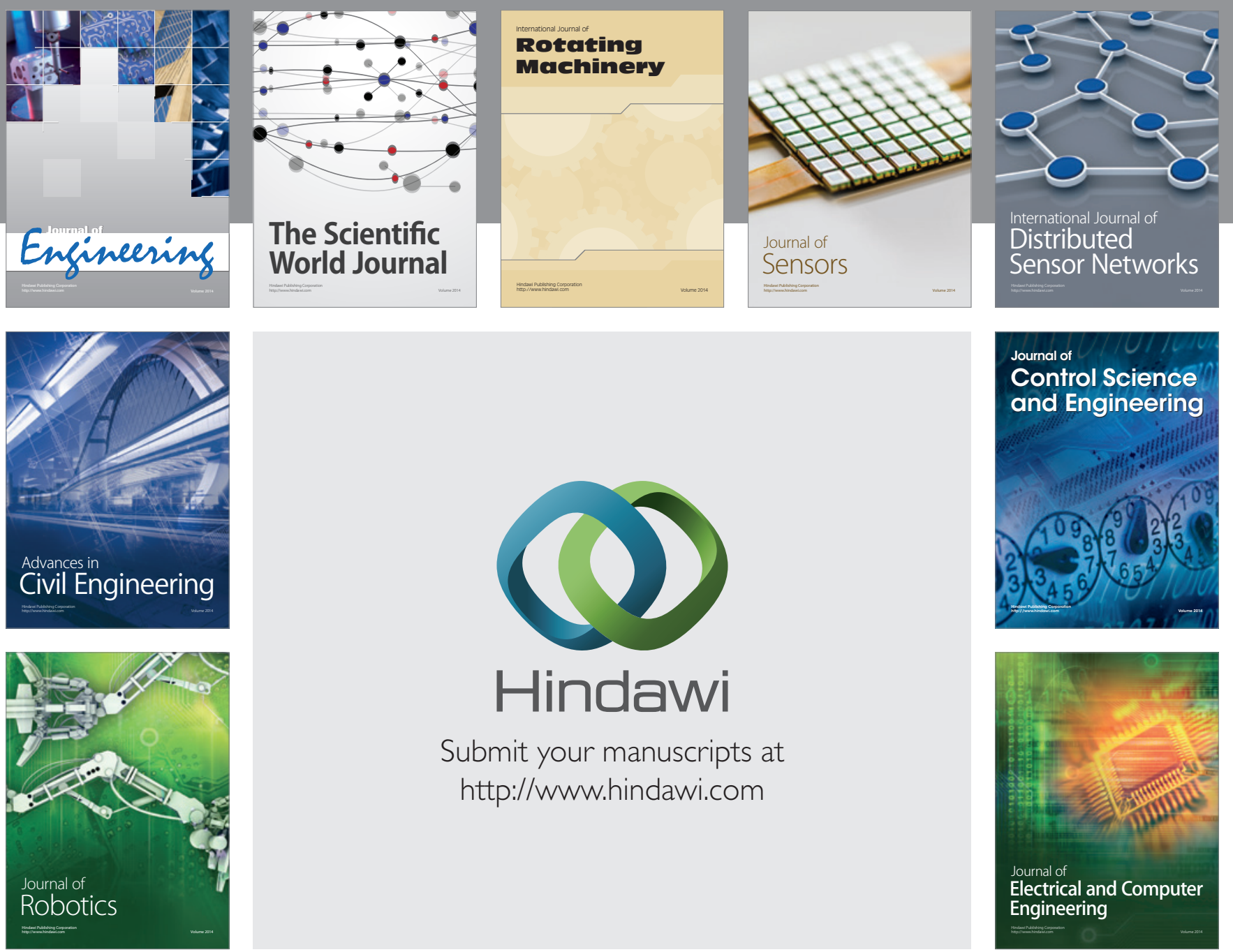

Submit your manuscripts at

http://www.hindawi.com
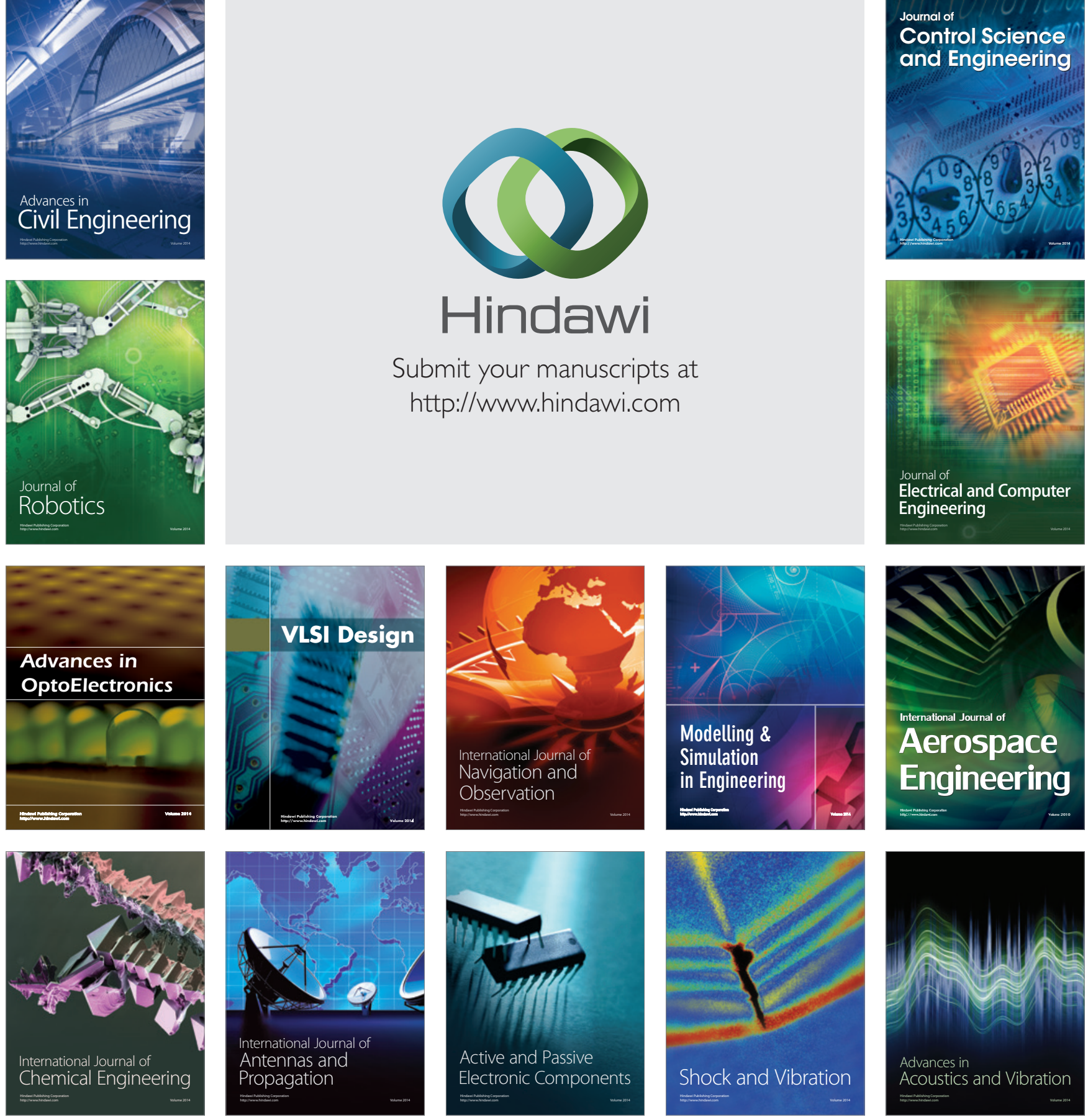